\title{
Multivariate-based classification of predicting cooking quality ideotypes in rice (Oryza sativa L.) indica germplasm
}

\author{
Rosa Paula O. Cuevas $^{1 *}$, Cyril John Domingo ${ }^{1,2}$ and Nese Sreenivasulu ${ }^{1 *}$ (D)
}

\begin{abstract}
Background: For predicting texture suited for South and South East Asia, most of the breeding programs tend to focus on developing rice varieties with intermediate to high amylose content in indica subspecies. However, varieties within the high amylose content class may still be distinguishable by consumers, who are able to distinguish texture that cannot be differentiated by proxy cooking quality indicators.

Results: This study explored a suite of assays to capture viscosity, rheometric, and mechanical texture parameters for characterising cooked rice texture in a set of 211 rice accessions from a diversity panel and employed multivariate approaches to classify rice varieties into distinct cooking quality classes. Results suggest that when the amylose content range is narrowed to the intermediate to high classes, parameters determined by rheometry and RVA become diagnostic. Modeled parameters distinguishing cooking quality ideotypes within the same range of amylose classes differ in textural parameters scored by a descriptive sensory panel.

Conclusions: Our results reinforced the notion that it is important to define cooking quality classes in indica subtypes based on multidimensional parameters, by going beyond amylose predictions. These predictive cooking models will be handy in capturing cooking and eating quality properties that address consumer preferences in future breeding programs. Policy implications of such findings may lead to changes in criteria used in assessing grain quality in the intermediate to high amylose classes.
\end{abstract}

Keywords: Grain quality, rapid Visco-analysis (RVA), random forest model, Rheology, Texture profile analysis

\section{Background}

In rice varietal improvement programs, the texture of cooked rice is primarily indicated by amylose content (AC) [Juliano 2006; Juliano et al. 2009]. This parameter is used to classify rice into five AC classes associated with cooked rice texture: waxy $(0-2 \%)$, very low (3-9\%), low (10-19\%), intermediate (20-25\%), and high (>25\%) [Kumar and Khush 1986a; Kumar and Khush 1986b]. However, samples in the same AC class could have different sensory profiles [Champagne et al. 2010], which suggest that within an AC class, rice varieties are still quite diverse in terms of cooking and eating quality. Attempts to fine-tune rice characterisation include introducing gel consistency

\footnotetext{
* Correspondence: r.cuevas@irri.org; n.sreenivasulu@irri.org

${ }^{1}$ International Rice Research Institute (IRRI), College, Los Baños, Laguna,

Philippines

Full list of author information is available at the end of the article
}

(GC) data to differentiate high-AC rice into soft and hard classes [Cagampang et al. 1973]; and gelatinisation temperature (GT) to further differentiate samples within an AC class into different GT classes [e.g.,Yang et al. 2014; Pang et al. 2016]. Hence, rice variety development and improvement programs use these $\mathrm{AC}$, GT, and GC indicators to develop breeding targets for specific markets. Other attributes, such as pasting properties and mechanical textural properties of rice varieties, also provide further insights into cooked rice texture. However, many of the findings still point to associations of texture with AC [e.g., Li et al. 2017; Hori et al. 2016; Tran et al. 2011; Li et al. 2016]; thereby effectively masking associations among these attributes with the diversity of rice germplasm within an $\mathrm{AC}$ class. It must be noted that many of the past studies used narrow ranges of germplasm to perform 
associations within each AC class [e.g.,Yang et al. 2014; Tuaño et al. 2014; Garcia et al. 2011].

One of the best ways to determine the associations of other cooking quality factors with texture is to make AC a constant in studies. An approach is to focus analyses on waxy rice varieties, which have negligible concentrations of amylose. However, the global waxy rice market is small (only $1 \%$ of the rice trade); thus the waxy rice approach is not widely used [Calpe 2004]. The biggest market share for rice comes from those who prefer varieties with intermediate to high AC in South Asia and South East Asia [Tuaño et al. 2016; Calingacion et al. 2014]. Hence, insights on diversity of textural attributes would be most valuable from studies that focused on varieties coming from these two AC classes.

Information about other cooking quality attributes within an AC class may be obtained by further characterising the behaviour of starch during the cooking and the cooling process. Rapid Visco-Analysis (RVA) is routinely used to determine the pasting behaviour of starchwater suspensions. The pasting curve provides metrics that indicate disintegration and retrogradation of starch, and is based on rheological principles [Zaidul et al. 2007; Fitzgerald et al. 2003; Doutch et al. 2012]. These metrics include peak viscosity (PV, the maximum viscosity registered during the heating-holding stages), trough viscosity ( $\mathrm{TV}$, the minimum viscosity after $\mathrm{PV}$ ), final viscosity ( $\mathrm{FV}$, the viscosity measurement at the end of the cooling stage), breakdown (BD, the difference between PV and TV), lift-off (LO, the difference between $\mathrm{TV}$ and FV), and setback (SB, the difference between FV and PV). The pasting curve also shows the pasting temperature (PTemp, temperature at the point at which the viscosity increase is greater than the set point for viscosity change rate) and the peak time (PT, the time it took to reach PV) [Fitzgerald et al. 2003; Bao 2008]. On the other hand, reports of viscoelastic properties of starch pastes via rheometry typically mention the values for maximum storage modulus $\left(G_{\max }^{\prime}\right)$ and feature the curves for G', loss modulus (G"), and $\tan (\delta)$ [Hsu et al. 2000; Iturriaga et al. 2006; Tsai and Lii 2000]. Extracting more information from the viscoelastic curves could provide information about the diversity of rice varieties within the same AC class.

Texture parameters could be classified into three types: geometrical properties, mechanical properties, and properties related to moisture and fat content [Brandt et al. 1963]. Texture profiling using the Texture Analyser focuses on mechanical attributes. For cooked rice, four mechanical attributes measured by the Texture Analyser are applicable: hardness, adhesiveness, cohesiveness, and springiness [Champagne et al. 1998]. These mechanical attributes could provide more dimensions in rice characterisation within the same AC class.
Classification of diverse germplasm within intermediate and high AC classes based on multidimensional data such as those generated by RVA, rheometry, and texture analysis will shed interesting insights about cooking and eating quality. Such insights could then be obtained through dimension reduction and correlation studies applied to multidimensional cooking quality data. Predicted cooking quality classes can also be used to determine grain quality attributes that affect the market prices of rice varieties [e.g., Cuevas et al. 2016; Unnevehr et al. 1985].

In this study, multinomial logistic regression and random forests are the data mining techniques that were employed. The multinomial logistic regression is an extension of the binary logistic regression, a technique used to calculate the probability of membership in one of more than two nominal or unordered categories (outcome variables) based on maximum likelihood estimation [Dixit et al. 2015, reviewed in Madhu et al. 2014]. Random forests, on the other hand, is a prediction tool composed of a combination of decision trees that can be used for classification and to measure the importance of variables [Breiman 2001]. The importance of a variable is estimated based on increases in prediction error when the data for that variable is permuted while the data for other variables are kept unchanged [Liaw and Wiener 2002]. In other words, an important variable that has a considerable effect on the accuracy of classification can be identified through a random forest model [Ziegler and König 2014].

To the best of our knowledge, these data mining techniques have not been applied to classify rice accessions based on cooking and organoleptic attributes. The objectives of this study, therefore, were to (1) characterise the textural and cooking properties of a collection of rice varieties belonging to the intermediate- and to the high-AC classes; and (2) apply modeling techniques to predict distinct cooking quality ideotypes based on visco-elastic and textural attributes.

\section{Methods}

\section{Rice varieties}

A set $(n=211)$ of indica rice accessions was selected based on genetic diversity and their geographic distribution, listed as Additional file 1: Table S4. These varieties were planted and grown during the dry season of 2014 under field conditions at IRRI by following the standard agronomic practices. The paddy grains were harvested at maturity and the samples were then stored to equilibrate moisture content to $14 \%$. The samples were then dehulled (Rice sheller THU-35A, Satake Corporation, Hiroshima, Japan) and milled (Grainman 60-230-602AT, Grain Machinery Mfg. Corp., Miami, USA). A test portion (100 unbroken grains) from each sample was set aside for texture profile analyses (TPA) and the rest of 
the sample was ground to fine powder (Cyclone Sample Mill 3010-030, Udy Corporation, Fort Collins, USA). The homogenized rice flour was used for various biochemical analyses.

\section{Amylose content measurement}

Amylose content (AC) was determined based on the colorimetric reaction of the amylose-iodine complex developed using the method of ISO 6647 [International Organization for Standardization 2007a, 2007b]. In brief, $100 \mathrm{mg}$ flour was suspended in ethanol $(1 \mathrm{~mL})$ and sodium hydroxide $(9 \mathrm{~mL}, 1 \mathrm{~N})$. The suspension was then heated $\left(95^{\circ} \mathrm{C}, 10 \mathrm{~min}\right)$ to gelatinise the starch. Then, the sample was cooled to room temperature and the volume of the suspension was made up to $100 \mathrm{~mL}$ using deionised water. The starch in the gelatinised sample was injected into the glass transition lines of a San ++ Segmented Flow Analyser (SFA) system (Skalar Analytical B.V., AA Breda, The Netherlands); it was allowed to react with an aqueous solution containing $10 \% \mathrm{CH}_{3} \mathrm{COOH}(1 \mathrm{~N})$ and $30 \% \mathrm{KI}^{-\mathrm{I}_{2}}$ (2\%:0.2\%) to form amylose-iodine complex. Absorbance of the sample's amylose-iodine complex was measured at a wavelength of $620 \mathrm{~nm}$ and $\mathrm{AC}$ was quantified from a standard curve using varieties of known ACs (IR65, IR24, IR64, and IR8). The ACs of the varieties used in the standard curve were determined using the reference method of ISO 6647 [International Organization for Standardization 2007a, 2007b]. Samples were then classified into $\mathrm{AC}$ classes using the $\mathrm{AC}$ ranges previously reported [Graham 2002].

\section{Gelatinisation temperature (GT) measurement}

The GT of the rice samples were characterised through differential scanning calorimetry (DSC) as previously described [Cuevas et al. 2010]. In brief, milled rice flour (4 mg) was immersed in water $(8 \mathrm{mg})$ and the suspension was hermetically sealed in aluminum pans. The sealed pans were then heated $\left(25-120{ }^{\circ} \mathrm{C}\right)$, with temperature being increased at a rate of $10{ }^{\circ} \mathrm{C} \mathrm{min}^{-1}$, using a DSC model Q100 (TA Instruments, DE, USA). Data on thermal transitions were collected and analysed using the Universal Analysis 2000 software. The peak of the endotherm was reported as the GT. Samples were classified as low-GT (below $67{ }^{\circ} \mathrm{C}$ ), as intermediate-GT $\left(68-73{ }^{\circ} \mathrm{C}\right)$, and as high-GT $\left(\mathrm{GT} \geq 74{ }^{\circ} \mathrm{C}\right)$ [Cuevas et al. 2010; Musyoki et al. 2015].

\section{Rapid Visco-analyses}

Rice flour (3 g) was suspended in reverse osmosis-purified (RO) water ( $25 \mathrm{~g})$ in a canister and viscosity changes were then measured using a Rapid Visco Analyzer (RVA, Model 4-D, Newport Scientific, Warriewood, Australia), following the heat $\left(50-95{ }^{\circ} \mathrm{C}\right)-$ hold $\left(95^{\circ} \mathrm{C}\right)-\operatorname{cool}\left(95-50{ }^{\circ} \mathrm{C}\right)$ time/temperature profile described in the AACC Method
61-02 [American Association of Cereal Chemists Inc 2000]. The time/temperature profile was controlled and the data was collected and processed using the ThermoCline for Windows (TCW) version 2.6.

\section{Rheometry}

For each sample, rice flour was suspended in reverse-osmosis water $(1: 2(w / v))$ and then placed at the centre of a Peltier plate of the Advanced Rheometer 2000 (TA Instruments, New Castle, DE). The rheometer was fitted with a parallel plate geometry $(\varnothing=40 \mathrm{~mm})$. To minimise evaporation during the test, the sample was covered with a solvent trap sealed with water. During the test, the sample was subjected to heating ramp $\left(35-95^{\circ} \mathrm{C}\right)$ at $4{ }^{\circ}$ $\mathrm{C} \mathrm{min}^{-1}$ ramp rate then to a cooling ramp $\left(95-35^{\circ} \mathrm{C}\right)$ at the same ramp rate. The frequency of oscillation was set at 1 cycle per second $(1 \mathrm{~Hz})$. Measurements were performed in triplicate. The TA Advantage Software 2003 (version 4.0.0) was used to record the data (Table 1). Additional parameters were calculated using Microsoft Excel 2013 (Table 1, Additional file 2: Figure S1). The temperature at the gelation point (i.e., the crossover point where $\tan (\delta)=1)$, the loss modulus $\left(G^{\prime \prime}\right)$ at $G_{\max }^{\prime}$, the $\tan (\delta)$ at $G_{\max }^{\prime}$ (the ratio of $G^{\prime \prime}$ to $G^{\prime}$ at $G_{\max }^{\prime}$ ), and the temperature at $G_{\max }^{\prime}$ were determined based on the G' and the G" curves. Slopes 1 and 3 (S1 and S3) were measured from the gel point (where $\tan (\delta)=1$ ) to $G_{\text {max }}^{\prime}$ and $G^{\prime \prime}{ }_{\max }$. Slope 2 (S2) was measured at $G_{\max }^{\prime}$ to the lowest point of the decreasing $G^{\prime}\left(G_{\text {trough }}^{\prime}\right)$ while Slope 4 (S4) was measured from $G^{\prime \prime}{ }_{\max }$ to the point before the G" leveled off.

Table 1 Description of the viscoelastic properties measured via rheometry [Hsu et al. 2000; Ahmed et al. 2008; Mandala 2012]

\begin{tabular}{|c|c|}
\hline Parameter & Description \\
\hline $\begin{array}{l}\text { Storage Modulus } \\
\max \left(G_{\max }^{\prime}\right)\end{array}$ & Maximum energy stored was reached. \\
\hline $\begin{array}{l}\text { Loss modulus }\left(G^{\prime \prime}\right) \\
\text { at } G_{\max }^{\prime}\end{array}$ & Energy loss at $G_{\text {max. }}^{\prime}$ \\
\hline $\operatorname{Tan}(\delta)$ at $G_{\max }^{\prime}$ & $\begin{array}{l}\text { Variable that describes behavior of the sample } \\
\text { (solid- or liquid- like). }\end{array}$ \\
\hline $\begin{array}{l}\text { Temperature at } \\
\text { gelation point (tan } \\
(\delta)=1 \text { ) }\end{array}$ & $\begin{array}{l}\text { Temperature measured at point where } \mathrm{G}^{\prime} \text { and } \mathrm{G}^{\prime \prime} \\
\text { crossed over and the point at which } \tan (\delta)=1 \text {. }\end{array}$ \\
\hline $\begin{array}{l}\text { Peak temperature } \\
G^{\prime}\end{array}$ & Temperature measured when the $G_{\max }^{\prime}$ is reached. \\
\hline${ }^{\mathrm{a}}$ Slope 1 (S1) & Rate of change of $G^{\prime}$ from the gelation point to $G_{\text {max }}^{\prime}$ \\
\hline aslope 2 (S2) & $\begin{array}{l}\text { Rate of change of } G^{\prime} \text { from } G_{\max }^{\prime} \text { to the lowest point } \\
\text { of the decreasing } G^{\prime}(P 1)\end{array}$ \\
\hline aslope 3 (S3) & Rate of change of $G^{\prime \prime}$ from the gelation point to $G_{\text {max }}^{\prime \prime}$ \\
\hline aslope 4 (S4) & $\begin{array}{l}\text { Rate of change of } G^{\prime \prime} \text { from } G_{\text {max }}^{\prime \prime} \text { to the point before } \\
\text { the } G^{\prime \prime} \text { levels off. }\end{array}$ \\
\hline${ }^{\mathrm{a}} G_{\text {trough }}^{\prime}$ & Lowest point after $G_{\max }^{\prime}$ \\
\hline
\end{tabular}

afeatures of the viscoelastic curves that are not routinely measured, according to literature 


\section{Texture profile analyses}

For each sample, 25 unbroken milled rice grains were submerged in $1 \mathrm{~mL}$ water for $15 \mathrm{~min}$ in a test tube, which was then covered to minimise water evaporation. The test tube was heated in a boiling water bath $(20 \mathrm{~min})$ and then placed in a water bath $\left(50{ }^{\circ} \mathrm{C}\right)$ until texture profile analysis. Three cooking replications were conducted. Three cooked unbroken rice grains were subjected to a two-cycle compression test using a TA.XT-Plus Texture Analyser equipped with a cylindrical probe $(\varnothing=35 \mathrm{~mm}$, Stable Micro Systems Ltd., Surry, UK). The texture profile resulting from this two-compression test is composed of two sets of one positive and one negative curves, which can be divided into regions that represent downstrokes (increasing values) and upstrokes (decreasing values) (Additional file 2: Figure S2). Hardness (HRD, the peak of the first positive curve), adhesiveness (ADH, the area under the negative curve, representing the work required to pull the plunger from the sample on the base plate), cohesiveness $(\mathrm{COH}$, the ratio of the area of the second positive curve to that of the first positive curve), and springiness (SPR, the ratio of the time elapsed from the upstroke to the peak in the second curve (T2) to the time elapsed from starting point to the peak of the first curve (T1), representing sample height recovery after the initial compression) [Lyon et al. 2000]. These parameters were measured at $90 \%$ strain and test speed at $0.5 \mathrm{~mm} \mathrm{~s}^{-1}$. For each cooking replicate, three compression replicates were conducted.

\section{Protein content measurement}

Crude protein content (PC) was measured using a modified protocol based on the automated colorimetric method (AACC Method 46-09) [AACC 2000]. A test portion of flour $(50 \mathrm{mg})$ was digested in sulphuric acid $(2 \mathrm{~mL})$ with $1 \mathrm{~g}$ anhydrous potassium sulphate:selenium mixture $(50: 1, w / w)$ for $1 \mathrm{~h}$ at $370{ }^{\circ} \mathrm{C}$. The sample was then cooled to room temperature and made up to volume $(20 \mathrm{~mL})$ with deionised water. It was kept overnight to allow for sedimentation. The liberated ammonium in the digest was then allowed to react with a solution containing sodium salicylate $(0.94 \mathrm{M})$ and sodium nitroprusside $(0.00026 \mathrm{M})$, and aqueous sodium hypochlorite $(0.525 \%$, also contained $30 \%$ Brij-35) while going through the glass transition lines in a San ++ Segmented Flow Analyser (SFA) system at $16 \mathrm{~mL} \mathrm{~min}^{-1}$. Absorbance values of the ammonia-salicylate complex were determined at $\lambda=$ $660 \mathrm{~nm}$. The \% Kjeldahl $\mathrm{N}$ values of the samples were determined based on the linear relationship between absorbance and analyte concentration, following the Beer-Lambert Law. This linear relationship was based on a standard curve developed using ammonium sulfate solutions with different concentrations. The crude PC was calculated by multiplying the Kjeldahl N value by 5.95 [Villareal et al. 1991].

\section{Statistics}

Statistical analyses were carried out in $\mathrm{R}$ (version 3.3.2, released 2016). Ward's cluster analysis was used to group the samples into three clusters based on 25 variables (AC, PC, RVA, advanced rheometry, and texture parameters). The raw dataset was used in developing a multinomial logistic regression (MLR) model to identify different clusters using Eq. 1:

$$
f(X i, k)=\beta k \cdot X i
$$

where $f\left(\mathrm{X}_{i}, k\right)$ is the score associated with the sample $i$ assigned to cluster $k$ (a non-binary categorical response variable), $\beta_{k}$ is the vector of regression coefficients associated with cluster $k$, and $\mathrm{X}_{i}$ is the vector of explanatory variables describing sample $i$.

Tests of random forests (RF) were conducted with 500 trees and three variables randomly selected at each split. These random forests generated standardised scores that indicated the importance of each of the nine retained variables (determined by MLR) in classifying samples into the three clusters and also identified the most important variables per cluster. To rank the variables according to importance, the random forest algorithm determined the magnitude of increase in the prediction error (i.e., decrease in prediction accuracy) when the out-of-bag data were permuted (or excluded) for one variable while data for all other variables were held constant [Liaw and Wiener 2002; Louppe et al. 2013]. Hence, variables that had higher changes in magnitude of increases in prediction error were deemed more important than those variables that tend to have lower magnitudes.

\section{Sensory evaluation}

Five samples from each cluster were selected for sensory evaluation using the texture profiling method [Lyon et al. 2000]. Milled grains from each sample were cooked using a 1:1 $(\mathrm{v} / \mathrm{v})$ ratio with water in rice cookers $(0.6 \mathrm{~L}$, Micromatic Model MRC-350). After the rice was cooked to completion, the rice was mixed, ensuring that the grains touching the sides and the bottom were undisturbed. Sub-samples were distributed into glass custard cups (pre-labelled with three-digit codes), sealed with a plastic lid, and then monadically presented for sensory evaluation to a previously trained set of panellists. Along with the sample, a tablespoon and a cup of drinking water were provided. To ensure that the samples were kept warm during the evaluation, the samples were kept in the rice cooker (at the "Warm" setting) and only 
Cuevas et al. Rice (2018) 11:56

Page 5 of 14

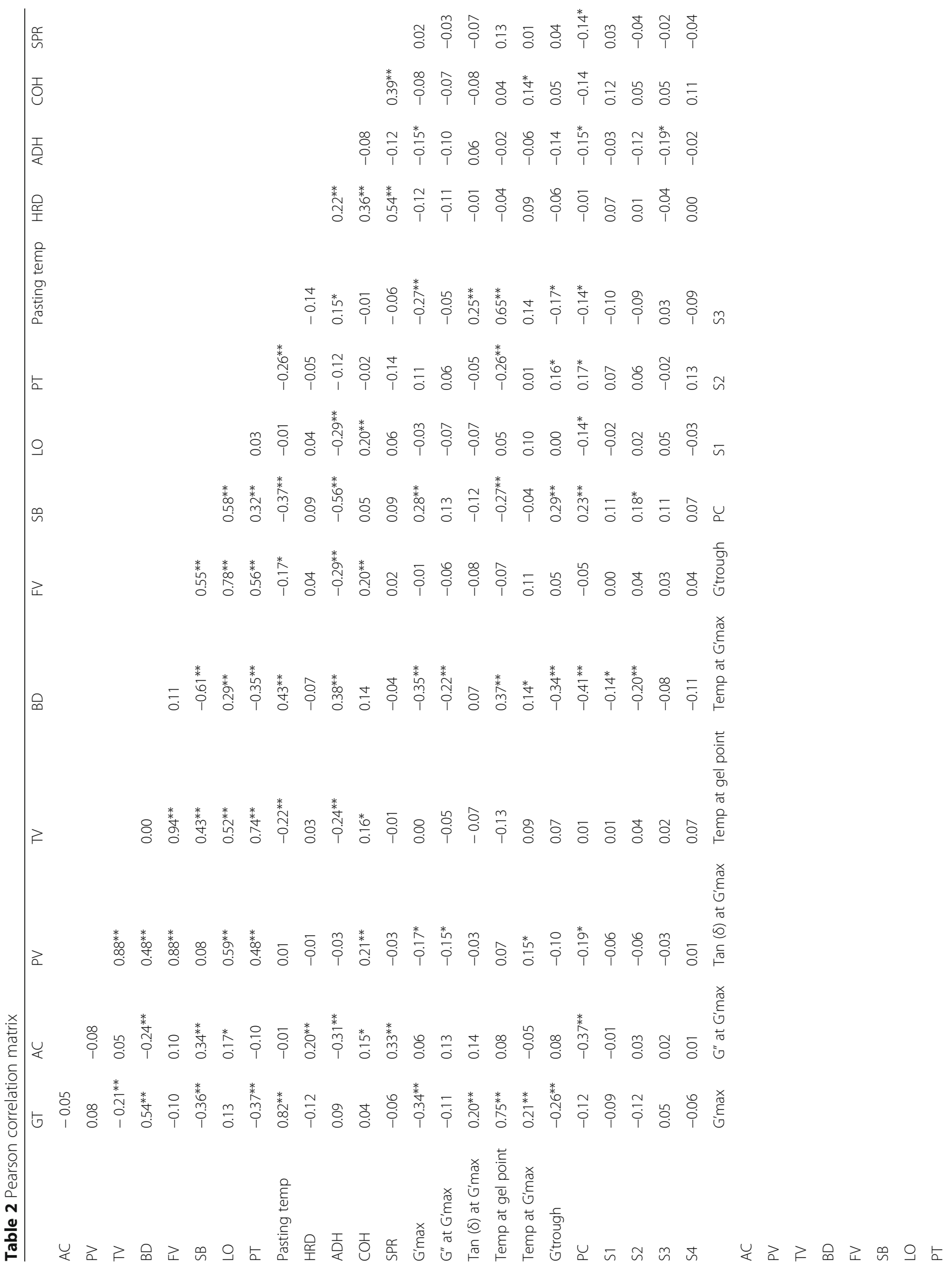


Cuevas et al. Rice (2018) 11:56

Page 6 of 14

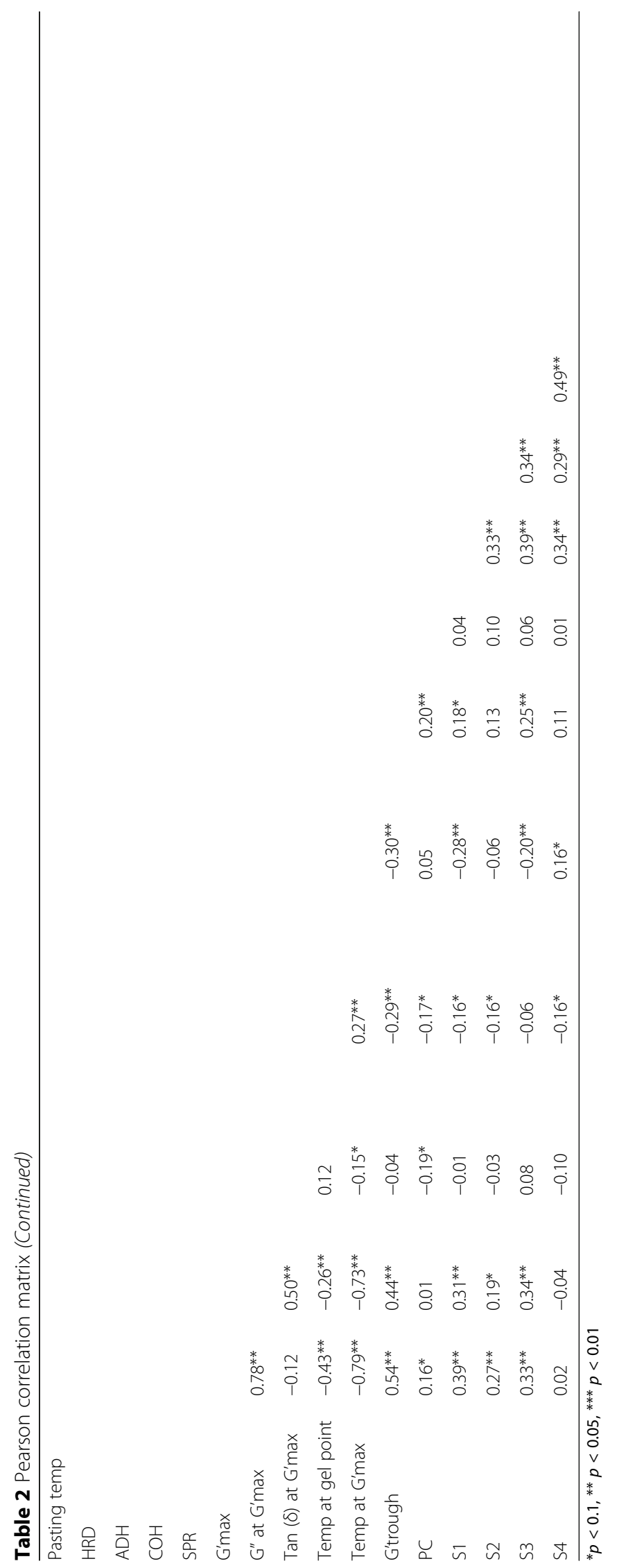


placed in sample cups once the panellists requested for the samples. A rice breeding line, IR06N155 (harvested in the dry season of 2013 at IRRI's Long-Term Continuous Cropping Experiment), was used as a standard. It was served to the panellists six times, randomly distributed in different rice tasting sessions.

The sensory panelists who participated in sensory evaluation were selected based on their availability and previous training in sensory descriptive profiling. The training phase included a battery of difference tests, sample and method familiarisation, and adjustment of the lexicon based on the panelists' contexts [Champagne et al. 2010]. The rice samples used in the training phase were commercially available milled rice sold as Sinandomeng, Jasmine, and Long-grain rice.

The attributes tested during the rice tasting sessions represented the texture perceived at various stages of eating rice: from when the rice grains are first placed in the mouth up to after swallowing the rice. Panellists evaluate the intensity of each attribute on a $150-\mathrm{mm}$ scale that has been adapted from established 15-point reference scales [Goodwin Jr. et al. 1996]. The R software was used for statistical analyses. Means and standard deviations were calculated per cluster.

\section{Results and discussion}

This study characterized cooking quality properties of 211 diverse rice accessions based on 25 cooking quality variables including those routinely tested in grain quality evaluation programs (AC, GT, PC, and RVA parameters) along with specialized traits to capture viscoelastic properties measured by rheometry (Table 1) and textural properties measured by TPA. Previous publications indicate that many of these variables are correlated [e.g., Chung et al. 2011, Singh et al. 2006, Bao et al. 2006, Allahgholipour et al. 2006, Vandeputte et al. 2003, Tan and Corke 2002, Xie et al. 2011, Martin and Fitzgerald 2002] and may thus be treated as redundant variables. In this study, it was determined that 10 of the 25 variables were highly correlated $(r>0.75$ or $r$ $<-0.75$, Table 2). Pasting temperature and temperature at the gel point were highly correlated with GT.

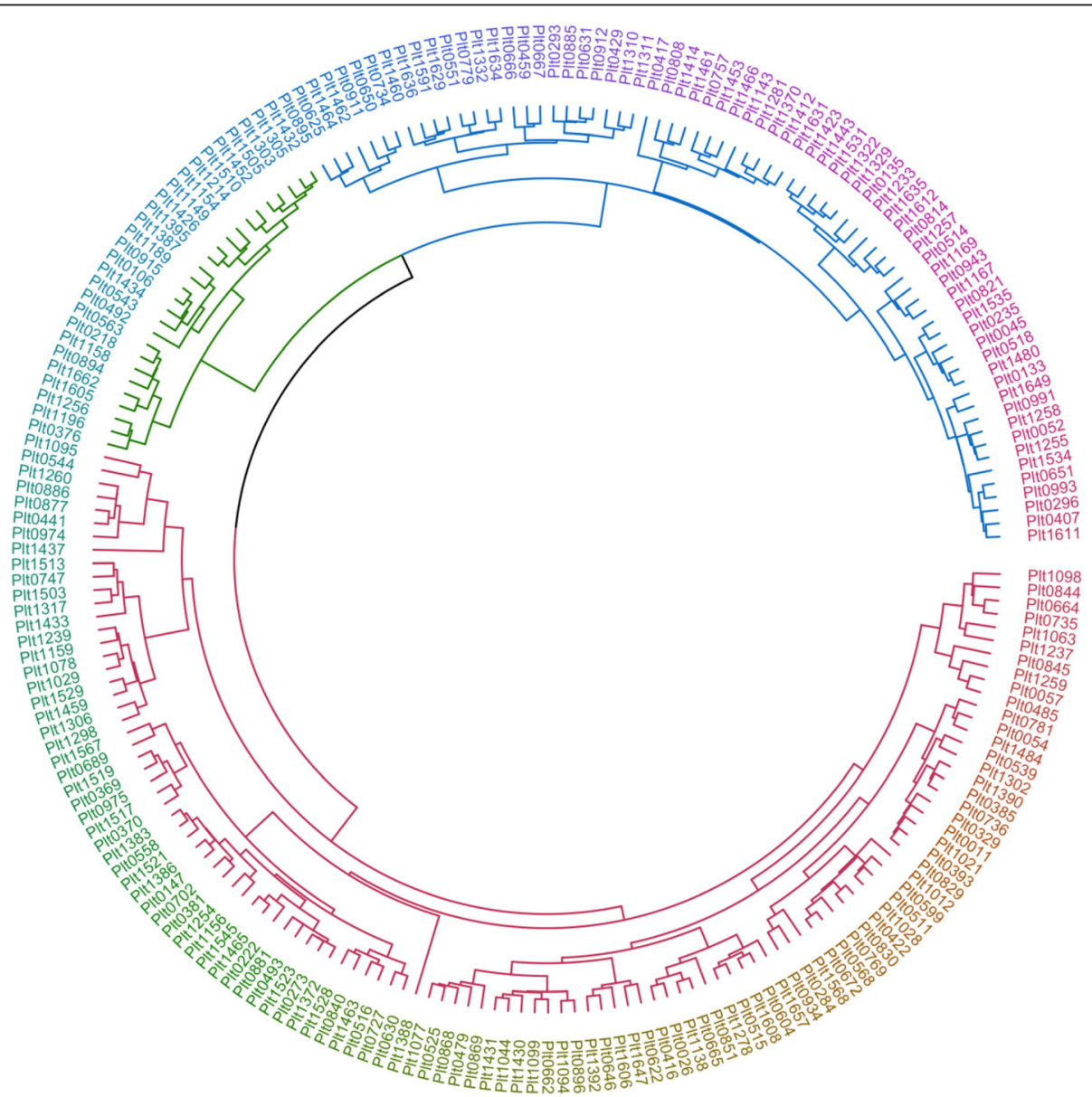

Fig. 1 Ward's cluster analysis indicates that the samples $(n=211)$ grouped into three clusters based on 19 grain quality attributes: $n_{1}=114$ (red), $\mathrm{n}_{2}=70$ (blue), $\mathrm{n}_{3}=27$ (green) 
Although peak viscosity (PV) was highly correlated with trough (TV) and final (FV) viscosities; FV was also highly correlated with lift-off (LO) and TV. In addition, $G_{\max }^{\prime}$ was positively correlated with $G^{\prime \prime}$ at $G^{\prime}{ }_{\max }$ and negatively correlated with temperature at $G^{\prime}{ }_{\max }$. Thus, six of these correlated attributes (PT, temperature at gel point, TV, FV, G" Temp at G $_{\max }$ ) were removed as redundant from the subsequent analyses and 19 variables were retained, including GT, LO, G' ${ }_{\max }$, and PV.

By employing Ward's cluster analysis to 19 variables (Table 2), three distinct clusters were identified (Fig. 1). Among them, cluster 1 was the biggest, with 114 samples, followed by cluster 2 with 70 samples, and by cluster 3 with 27 samples.

Clusters 1 and 2 have high AC; on the other hand, samples in cluster 3 could clearly be classified as intermediate AC (Table 3, Fig. 2a). Due to the similarities in ranges of $\mathrm{AC}$ between clusters 1 and 2, it is important to distinguish these two clusters based on visco-elastic parameters, through advance rheometry, and on textural attributes. In the past, rice samples with similar ACs have been reported to have distinguishable textural properties [e.g., Champagne et al. 2010; Champagne et al. 1999]; hence, it is important to explore other indicators of cooking behaviors' and organoleptic properties

Table 3 Means of 19 grain quality indicators of rice samples, by cluster. Standard deviations are indicated in parentheses

\begin{tabular}{|c|c|c|c|c|c|c|}
\hline \multirow{2}{*}{$\begin{array}{l}\text { Variable } \\
\text { GT }\left({ }^{\circ} \mathrm{C}\right)\end{array}$} & \multicolumn{2}{|c|}{$\begin{array}{l}\text { Cluster } 1 \\
(n=114)\end{array}$} & \multicolumn{2}{|c|}{$\begin{array}{l}\text { Cluster } 2 \\
(n=70)\end{array}$} & \multicolumn{2}{|c|}{$\begin{array}{l}\text { Cluster } 3 \\
(n=27)\end{array}$} \\
\hline & 74.81 & (3.98) & 77.10 & $(1.22)$ & 77.94 & $(1.38)$ \\
\hline$A C(\%)$ & 25.07 & (1.44) & 25.51 & (1.49) & 21.22 & $(1.24)$ \\
\hline$P V(P)$ & 2.23 & $(0.52)$ & 2.28 & $(0.43)$ & 2.49 & $(0.18)$ \\
\hline $\mathrm{BD}(\mathrm{P})$ & 0.67 & $(0.20)$ & 0.78 & $(0.14)$ & 1.10 & $(0.14)$ \\
\hline SB $(P)$ & 0.69 & $(0.21)$ & 0.61 & (0.18) & 0.15 & $(0.18)$ \\
\hline $\mathrm{LO}(\mathrm{P})$ & 1.36 & $(0.25)$ & 1.39 & $(0.19)$ & 1.24 & $(0.09)$ \\
\hline PT (min) & 5.96 & $(0.30)$ & 5.84 & $(0.18)$ & 5.89 & $(0.13)$ \\
\hline HRD (kg) & 1.96 & $(0.50)$ & 1.94 & $(0.50)$ & 1.73 & $(0.47)$ \\
\hline $\mathrm{ADH}(\mathrm{kg} \cdot \mathrm{sec})^{\mathrm{a}}$ & 0.02 & $(0.01)$ & 0.02 & $(0.01)$ & 0.04 & $(0.02)$ \\
\hline $\mathrm{COH}$ & 0.44 & $(0.06)$ & 0.42 & $(0.05)$ & 0.43 & $(0.04)$ \\
\hline SPR & 0.11 & $(0.02)$ & 0.11 & $(0.01)$ & 0.10 & $(0.01)$ \\
\hline $\mathrm{G}_{\max }^{\prime}(\mathrm{kPa})$ & 40.64 & (9.62) & 28.34 & $(7.20)$ & 29.83 & $(7.26)$ \\
\hline $\tan (\delta)$ at $\mathrm{G}_{\max }^{\prime}$ & 0.11 & $(0.02)$ & 0.12 & $(0.04)$ & 0.11 & $(0.02)$ \\
\hline $\mathrm{G}_{\text {trough }}^{\prime}(\mathrm{kPa})$ & 15.53 & $(4.31)$ & 11.92 & (2.33) & 11.66 & $(1.83)$ \\
\hline $\mathrm{S} 1$ (kPa/min) & 7.45 & (2.66) & 4.66 & $(1.88)$ & 5.93 & (2.49) \\
\hline $\mathrm{S} 2(\mathrm{kPa} / \mathrm{min})^{\mathrm{a}}$ & 1.66 & $(0.58)$ & 1.27 & (0.33) & 1.29 & $(0.22)$ \\
\hline $\mathrm{S} 3(\mathrm{kPa} / \mathrm{min})$ & 1.77 & $(0.70)$ & 1.19 & $(0.58)$ & 1.38 & $(0.63)$ \\
\hline $\mathrm{S} 4(\mathrm{kPa} / \mathrm{min})^{\mathrm{a}}$ & 1.53 & $(0.81)$ & 1.09 & $(0.63)$ & 1.24 & $(0.71)$ \\
\hline PC (\%) & 8.66 & $(1.26)$ & 8.34 & $(1.02)$ & 8.30 & $(1.00)$ \\
\hline
\end{tabular}

${ }^{a}$ Absolute values are indicated here because for these parameters, the negative (-) sign only indicates direction (i.e., up or down) rather than magnitude less than zero in order to fine tune how rice varieties within the high AC classes are classified.

Gelatinisation temperature is (GT) often regarded as one of the most important factors affecting cooked rice quality and it is often viewed in combination with $\mathrm{AC}$ because an increase in AC reportedly leads to elevated GT [Juliano et al. 2009; Yang et al. 2014]. In this study, cluster 2 (high AC) and cluster 3 (intermediate AC) were clearly classified as high GT; on the other hand, cluster 1 (high AC) has been classified as low GT (Fig. $2 a$, Table 3). This indicates that AC alone cannot contribute to increase in GT (Table 2). GT in addition, might potentially be influenced by medium chain length contribution of amylopectin (Miura et al. 2018). In this context, starch structure would play an important role to fine-tune the cooking quality ideotypes of the samples.

Protein content (PC) has been reported to affect cooked rice stickiness [Champagne et al. 2009] and surface hardness [Okadome 2005]. In this study, however, the averages of $\mathrm{PC}$ for the three clusters ranged from 8.30 to $8.66 \%$ (Table 3), suggesting that $\mathrm{PC}$ is probably not a discriminatory factor for clustering these samples. While clusters 2 and 3 had similar ranges of $\mathrm{PC}$, the cluster 1 appeared to have the widest range in PC (Fig. 2a). These results agree with a previously published report that PC was not an attribute that can differentiate cooking quality classes within rice collections [Bett-Garber et al. 2001].

The TPA provided measurements for HRD, ADH, $\mathrm{COH}$, and SPR. The three clusters had similar values for HRD (Table 3), with ranges also observed in waxy rice [Boualaphanh et al. 2011]. This indicates further that AC did not solely affect HRD for the samples in this study, as these two parameters are weakly correlated (Table 2). However, due to the similarities in values, HRD potentially could not define the three quality clusters. Diversity lines differ for $\mathrm{ADH}$ ranged from 0.02 to $0.04 \mathrm{~kg} \cdot \mathrm{sec}, \mathrm{COH}$ ranged from 0.42 to 0.44 , and SPR from 0.10 to 0.11 (Table 3). The box plots indicated that the ranges of the textural attributes represented in clusters 1 and 2 overlapped such that it was difficult to separate the two clusters from each other (Fig. 2b).

Pasting parameters are additional indicators of organoleptic quality, with parameters extensively studied particularly with their relationships with $\mathrm{AC}, \mathrm{PC}$, and mechanical texture attributes [reviewed in Champagne et al. 1999, Okadome et al. 2005, Yoenyongbuddhagal and Noomhorm 2002]. Results indicated that the clusters 1 and 2 exhibited similar averages for the different pasting parameters (Table 3); however, the averages for $\mathrm{BD}$ and SB clearly distinguish cluster 3 from the other two clusters (Table 3). Cluster 3 had the lowest 


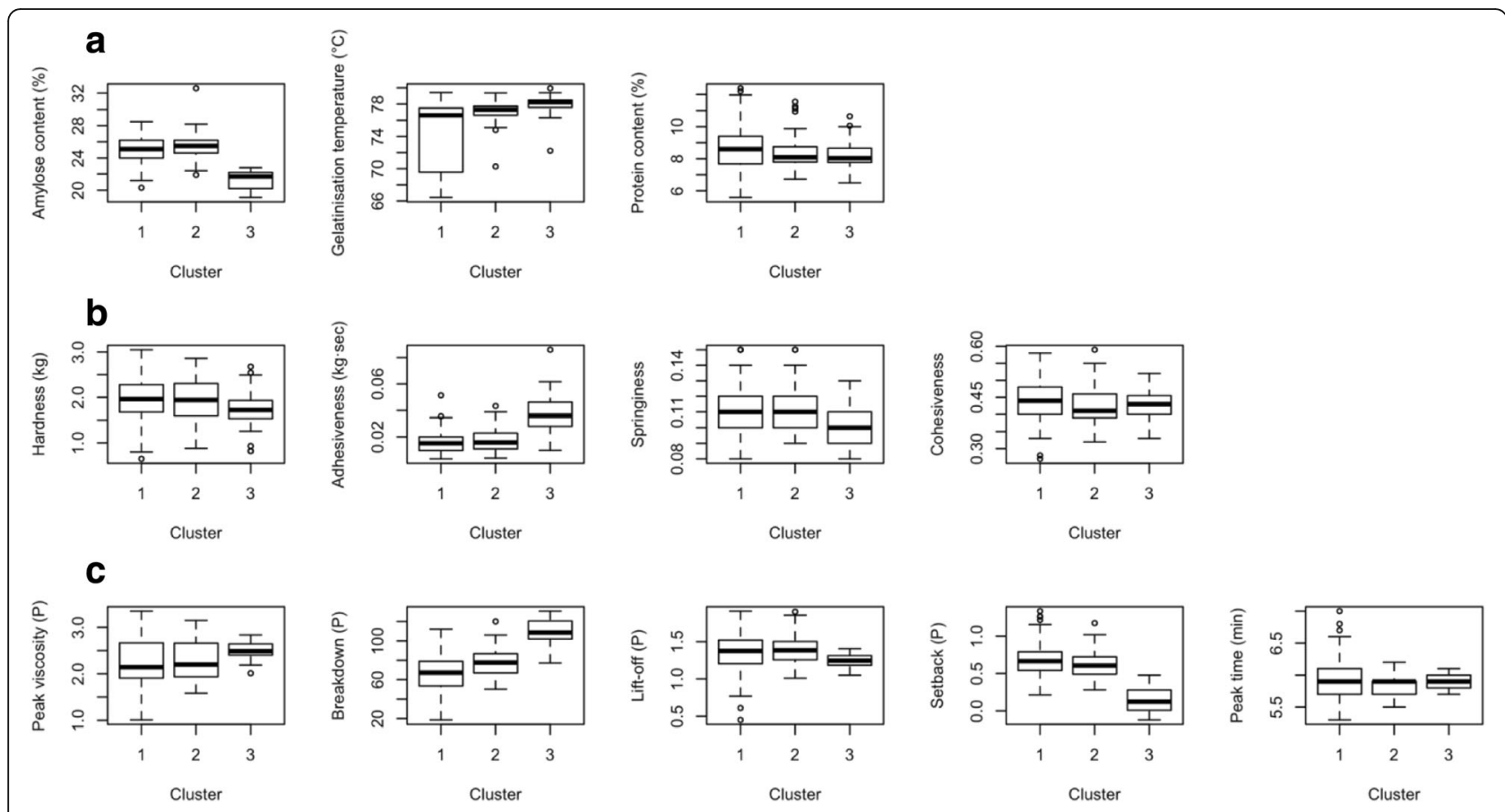

Fig. 2 Boxplots of the three clusters of rice samples for (a) GT, AC, and PC; (b) TPA parameters: HRD, ADH, COH, SPR; (c) RVA parameters PV, BD, LO, SB, and Peak time; and

setback among the three clusters (Table 3). This agrees with previous reports that indicate that setback and AC are correlated [e.g., Allahgholipour et al. 2006; Tan and Corke 2002; Chen et al. 2008]. Cluster 3 also has the highest BD (Table 3), indicating that the samples in this cluster are most resilient to continuous agitation stress.

Although most of the traditional grain quality parameters (AC, PC, GT and viscosity profiles of RVA) could not distinguish high-AC accessions represented within
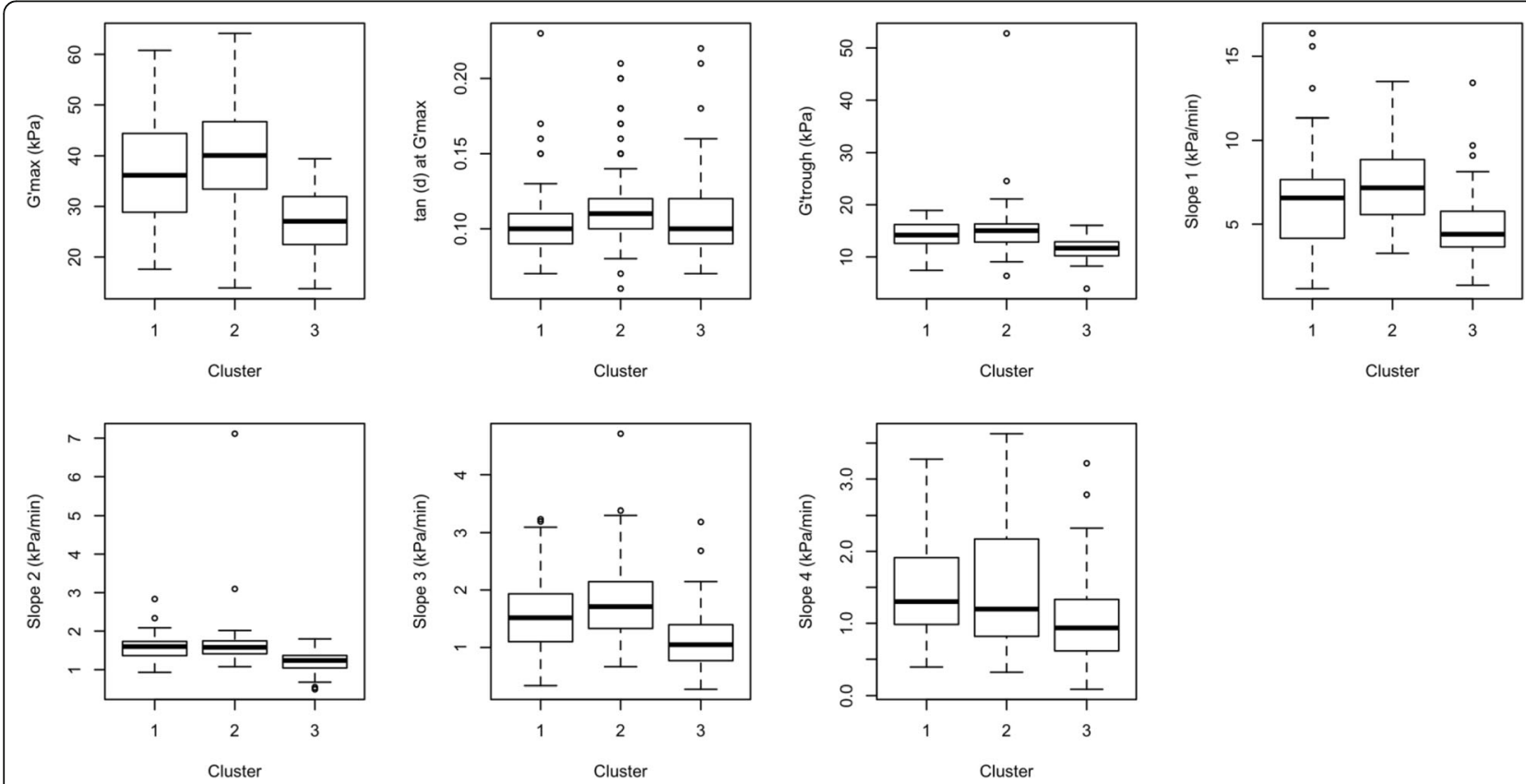

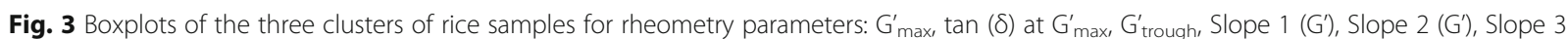
$\left(G^{\prime \prime}\right)$, Slope $4\left(G^{\prime \prime}\right)$ 
clusters 1 and 2, rheometry parameters have shown a nice range of differentiation between cluster 1 and 2 (Table 3 and Fig. 3). Cluster 1 represented lines had the highest averages for $G_{\max }^{\prime}$ and $G_{\text {trough }}^{\prime}$ while the other two clusters had similar values. Likewise, cluster 1 could clearly be distinguished from cluster 2 and cluster 3 based on S1, S2, S3, and S4 derived from the rheometer curves (Table 3 and Fig. 3).

In breeding programs, rice cooking quality classification is typically based on $\mathrm{AC}, \mathrm{GC}$, and GT considered individually [e.g., Juliano et al. 2009; Bett-Garber et al. 2001]. Although influence of AC on cooking quality is helpful when considering diverse rice collections containing both japonica and indica rice, the classical means of quality classification will probably not work when dealing with rice varieties within the same AC class in an indica germplasm collection. This study, therefore, used MLR (Eq. 1) in categorising the samples within the high-AC groups by including multiple variables in a classification model for cooking quality ideotypes. The "Forward Selection (Akaike Information Criterion, AIC)" allows stepwise selection to exclude the multi-collinear variables from the model. Through this step, 10 out of 19 variables were retained in the model, most of which were significant $(p<0.05)$ in the likelihood ratio test (Table 4). The 10 attributes which contributed significantly to the model included AC and GT from routine grain quality parameters; BD from RVA; $G_{\text {max }} \tan (\delta), G_{\text {trough }}^{\prime}$, S1, S2, and S3 from rheometry; and $\mathrm{COH}$ from TPA. The model has high classification accuracy $(93.84 \%$, Table 5) with sufficient explanatory power, as indicated by the change in 2Loglikelihood in the final model $\left(x^{2}=339.66, \mathrm{df}=18\right.$, $p<0.01$, Table 5). Also, the pseudo- $\mathrm{R}^{2}$ values indicate high levels of fit to differentiate clusters represented by cooking quality groups (Table 5 ).

Table 4 Likelihood ratio (LR) test

\begin{tabular}{lll}
\hline Variable & LR Chisq & $\operatorname{Pr}(>$ Chisq) \\
\hline $\mathrm{AC}$ & 58.95 & $<0.01^{* * *}$ \\
$\mathrm{G}_{\text {trough }}^{\prime}$ & 9.25 & $0.01^{* *}$ \\
$\mathrm{BD}$ & 7.80 & $0.02^{*}$ \\
$\mathrm{~S} 1$ & 20.87 & $<0.01^{* * *}$ \\
$\tan (\delta)$ at $\mathrm{G}_{\text {max }}^{\prime}$ & 24.06 & $<0.01^{* * *}$ \\
$\mathrm{~S} 3$ & 15.35 & $<0.01^{* * *}$ \\
$\mathrm{GT}$ & 13.30 & $<0.01^{* *}$ \\
$\mathrm{COH}$ & 13.91 & $<0.01^{* * *}$ \\
$\mathrm{G}_{\text {max }}^{\prime}$ & 9.95 & $0.01^{* *}$ \\
$\mathrm{~S} 2$ & 4.14 & 0.13 \\
\hline
\end{tabular}

${ }^{*} p<0.05,{ }^{* *} \mathrm{p}<0.01$

Degrees of Freedom $=2$
Table 5 Summary of multinomial logistic regression for variables characterising the different rice quality clusters. Cluster 1 is not shown in Table 5 because it is the reference cluster. Table 5 indicates the multinomial log-odds that samples represented in Cluster 2 or in Cluster 3, were compared to reference cluster 1 to calculate every unit increase or decrease in the different grain quality attributes included in the multinomial logistic regression model

\begin{tabular}{lllll}
\hline $\begin{array}{l}\text { Grain quality } \\
\text { attribute }\end{array}$ & \multicolumn{3}{l}{ Estimate } & \multicolumn{3}{l}{ Cluster 3 } \\
\cline { 2 - 5 } Cluster 2 & $(15.27)$ & 3.61 & $(0.08)^{* * *}$ \\
\hline Intercept & -25.51 & $(0.30)$ & -9.17 & $(2.94)^{* * *}$ \\
AC (\%) & 0.08 & $(0.19)^{*}$ & -1.48 & $(0.93)$ \\
$\mathrm{G}_{\text {trough }}^{\prime}$ & -0.33 & $(0.03)^{* *}$ & 0.72 & $(3.55)$ \\
$\mathrm{BD}$ & 0.06 & $(0.22)^{* * *}$ & -1.37 & $(3.20)$ \\
$\mathrm{S} 1$ & -0.88 & $(0.14)^{* * *}$ & 0.21 & $(11.71)$ \\
$\tan (\delta)$ at $\mathrm{G}_{\max }^{\prime}$ & 0.55 & $(0.84)^{* * *}$ & -0.12 & $(0.66)$ \\
$\mathrm{S} 3$ & -2.84 & $(0.18)^{* * *}$ & 2.03 & $(6.97)$ \\
$\mathrm{GT}$ & 0.54 & $(0.08)^{* * *}$ & 0.01 & $(11.97)$ \\
$\mathrm{COH}$ & -0.24 & $(0.06)^{* * *}$ & 0.22 & $(8.68)$ \\
$\mathrm{G}_{\max }^{\prime}$ & -0.15 & & 27 & \\
$\mathrm{~N}$ & 70 & &
\end{tabular}

Note: Total $\mathrm{N}=211 ; \mathrm{AIC}=106.20$; Overall classification accuracy: $93.84 \%$ Reference category for the regression model is cluster $1(n=114)$ Standard errors of the estimates are indicated in parentheses

${ }^{*} p<0.1,{ }^{* *} p<0.05,{ }^{* * *} p<0.01$.

Goodness-of-fit statistics: Residual Deviance $=66.20$; Degrees of freedom $=18$ -2Log-likelihood: The intercept-only model: 405.87; The final model: 66.20; $\mathrm{X}^{2}=339.66 ; p<0.01$

Pseudo- $R^{2}$ : McFadden $=0.84 ;$ Cragg \& Uhler $=0.94 ;$ Cox \& Snell $=0.80$

The magnitudes of the coefficients (i.e., multinomial log-odds) differed across clusters (Table 5); however, these do not indicate the importance of these variables in explaining the model. The relative importance of these variables was determined via random forest. Results show that $\mathrm{AC}$ was the most important variable in defining Cluster 3 (Fig. 4); this is expected because this cluster has the lowest AC values (Fig. 2a and Table 3). On the other hand, the two most important variables differentiating clusters 1 and 2 were rheometry parameters, $\mathrm{S} 1$ and $\mathrm{G}_{\text {max }}$. Amylose content ranked third in importance for both clusters, perhaps because AC can differentiate these two clusters from Cluster 3. The MLR model (Table 5) indicates that for every unit increase in $\mathrm{BD}, \tan (\delta)$ at $\mathrm{G}_{\max }$, and $\mathrm{GT}$, the multinomial log-odds distinguished accessions represented in cluster 1 from cluster 2. Meanwhile, for every unit increase in $\mathrm{G}_{\text {trough }}, \mathrm{S} 1, \mathrm{~S} 3, \mathrm{COH}$, and $\mathrm{G}_{\max }^{\prime}$, the multinomial log-odds that the sample belonged to cluster 2 rather than to cluster 1 decreased.

The capacity to differentiate between rice varieties within the same AC class through instrumental means becomes truly important if the differences can be detected by rice consumers. Hence, five samples from each cluster were subjected to descriptive profiling for texture 


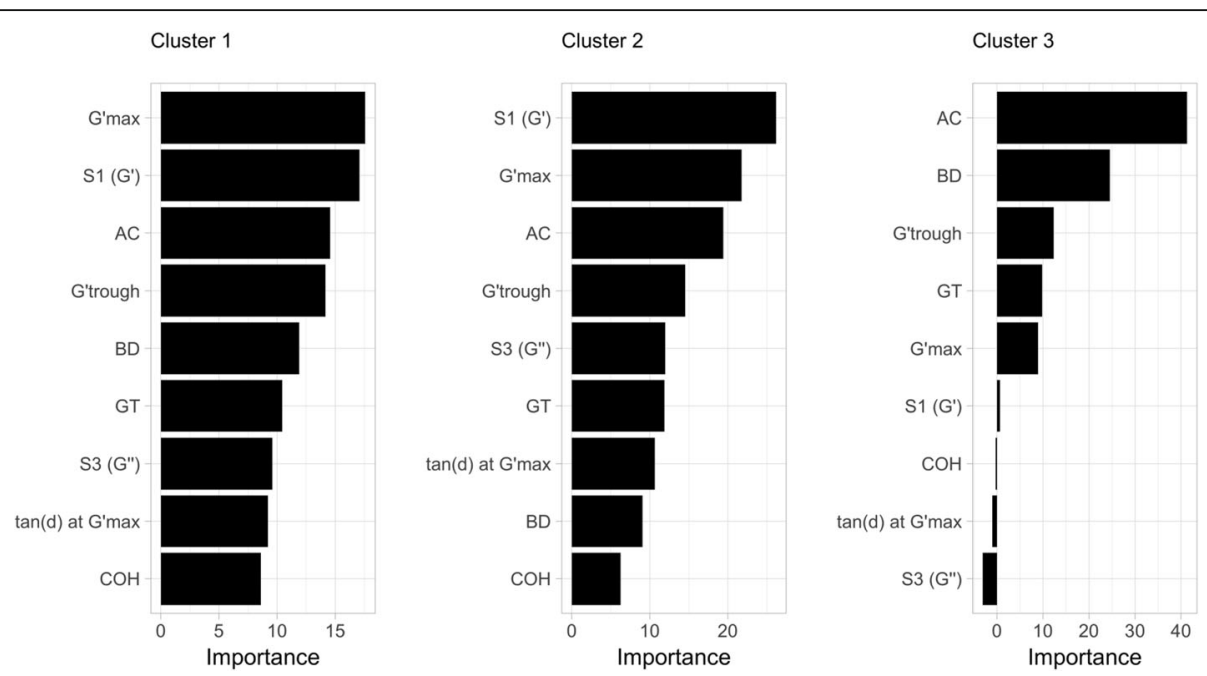

Fig. 4 Importance of the nine grain quality variables included in the final MLR model in each cluster, as calculated using Random Forests

by a trained sensory panel (Table 6, Additional file 3 : Table S1). The sensory profiles generated for textural attributes were compared (Fig. 5, Table 7). It was notable that clusters 1 and 2 had similar ranges of AC but had distinguishable sensory attributes. There was a remarkable difference between clusters 1 and 2 in terms of stickiness (both to the lips and between grains), cohesiveness, cohesiveness of mass, toothpack, and uniformity of bite. Furthermore, accessions representing cluster 1 were perceived to be slightly harder and springier than accessions from cluster 2, although both have high $\mathrm{AC}$

Table 6 Samples that underwent descriptive sensory profiling from the three clusters and their values for AC, GT, and PC. IDs linked to accession names have been described in Additional file 3: Table S1

\begin{tabular}{lllll}
\hline Cluster Number & Sample & AC (\%) & GT ( $\left.{ }^{\circ} \mathrm{C}\right)$ & PC (\%) \\
\hline 1 & GQ 00403 Plt 0057 & 24.5 & 68.44 & 8.27 \\
& GQ 01652 Plt 0222 & 24.6 & 77.92 & 8.03 \\
& GQ 01524 Plt 0369 & 27.4 & 76.88 & 6.55 \\
& GQ 01633 Plt 0370 & 27.2 & 76.44 & 6.84 \\
& GQ 01613 Plt 0493 & 26.3 & 77.81 & 7.74 \\
& GQ 00261 Plt 0885 & 26.8 & 76.60 & 9.40 \\
& GQ 00324 Plt 0993 & 25.2 & 77.75 & 8.63 \\
& GQ 00089 Plt 1143 & 25.5 & 76.89 & 8.33 \\
& GQ 00401 Plt 1167 & 23.9 & 77.17 & 11.13 \\
& GQ 00131 Plt 1414 & 25.0 & 78.45 & 7.38 \\
& GQ 01527 Plt 0106 & 22.7 & 78.24 & 7.74 \\
& GQ 01523 Plt 0218 & 20.5 & 77.58 & 7.91 \\
& GQ 01696 Plt 0376 & 19.4 & 78.65 & 8.63 \\
& GQ 01659 Plt 0492 & 19.9 & 78.43 & 8.33 \\
& GQ 01691 Plt 0543 & 22.7 & 79.94 & 6.49 \\
\hline
\end{tabular}

ranges. These results suggest that lines represented in clusters 1 and 2, distinguished initially based on rheometry and mechanical texture properties, could be differentiated by humans (Table 7). This further suggests that there may be relationships among force-related textural attributes perceived by people, rheological properties, and those attributes measured by texture profile analyses; and these attributes may distinguish lines with high-AC content. The differences in sensory profiles between clusters 1 and 3 appear to be related to moisture absorption, residual loose particles, and initial starchy coating (Fig. 5). Results also indicate that, despite the difference in AC class, accessions representing cluster 3 were similar to samples in cluster 1 in terms of cohesiveness, cohesiveness of mass, roughness, slickness, stickiness between grains, and toothpack. Attributes such as cohesiveness, cohesiveness of mass, toothpack, and uniformity of bite have not been explored as deeply as the force-related textural properties.

\section{Conclusions}

To predict cooking quality ideotypes of indica rice with intermediate-to-high $\mathrm{AC}$, we used 25 variables covering routine cooking quality predictors, RVA, rheometry, and instrumental texture profiling. Results showed that these intermediate- and high-AC samples could be classified into two distinct clusters using 19 variables. Clusters 1 and 2 both contained samples with high-AC while cluster 3 had samples with intermediate AC. This is the first study in which MLR was used to further differentiate high-AC samples using rheometry, TPA, and RVA parameters simultaneously. The differences in sensory profiles between the two clusters validate the use of rheometric properties as proxy metrics to distinguish cooking and eating quality within high-AC 

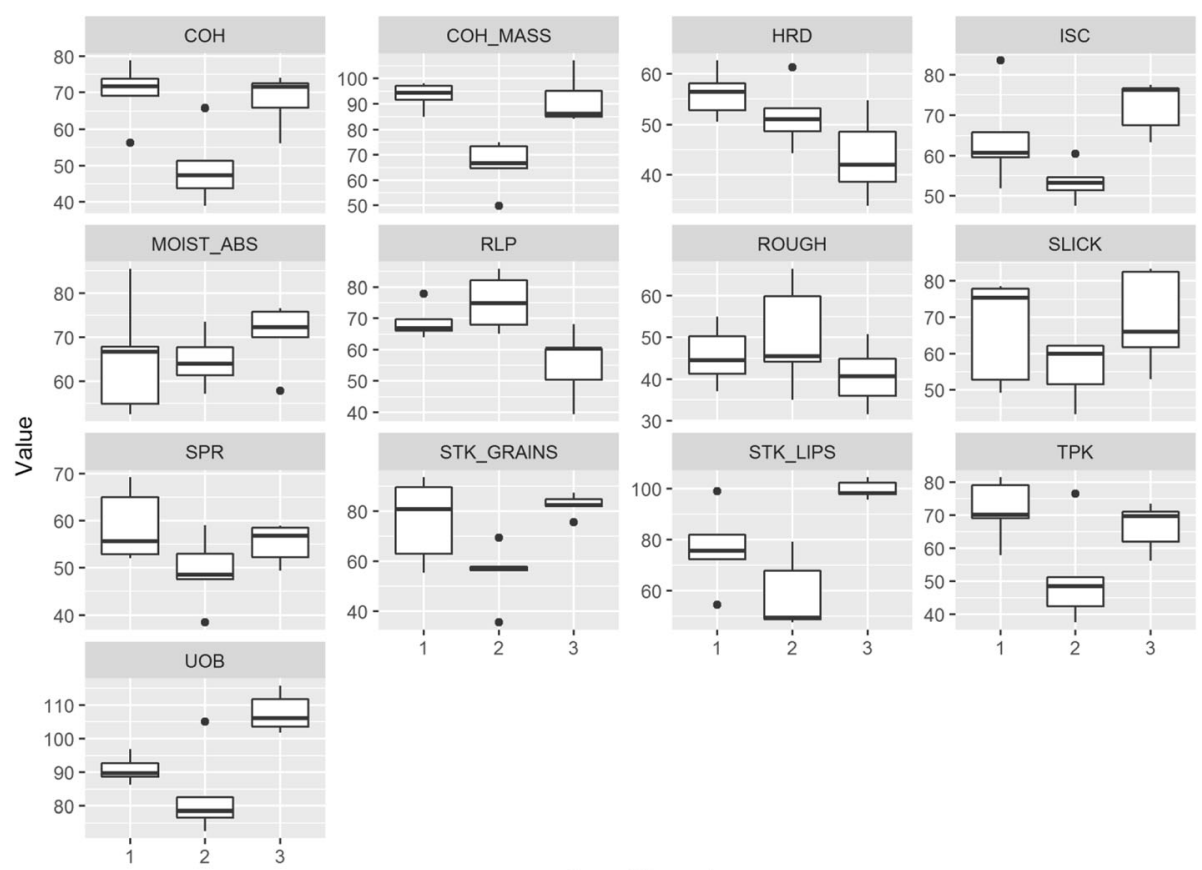

factor(Cluster)

Fig. 5 Box plots comparing the three clusters based on 13 texture attributes evaluated by sensory panelists based on a 150-mm scale. The sensory attributes [13] evaluated were: cohesiveness (COH), cohesiveness of mass (COH_MASS), hardness (HRD), initial starchy coating (ISC), moisture absorption (MOIST_ABS), residual loose particles (RLP), roughness (ROUGH), slickness (SLICK), springiness (SPR), stickiness between grains (STK_GRAINS), stickiness to the lips (STK_LIPS), toothpack (TPK), uniformity of bite (UOB)

ranges. This study calls for a deeper look into variables extracted from rheometry and descriptive sensory evaluation, as these could enhance our capacity to classify rice into quality classes that match consumer preferences. A deeper understanding about these attributes will be important as breeding strategies become

Table 7 Comparison of intensities of sensory attributes based on descriptive test conducted through panel evaluation

\begin{tabular}{llll}
\hline Sensory attribute & \multicolumn{3}{l}{ Cluster } \\
\cline { 2 - 4 } & 1 & 2 & 3 \\
\hline Initial starchy coating & $64.3 \pm 11.9$ & $53.4 \pm 4.8$ & $72.3 \pm 6.4$ \\
Slickness & $66.8 \pm 14.5$ & $55.8 \pm 8.3$ & $69.3 \pm 13.3$ \\
Roughness & $45.6 \pm 7.1$ & $50.2 \pm 12.7$ & $40.8 \pm 7.5$ \\
Stickiness to the lips & $76.7 \pm 16.1$ & $58.6 \pm 14.2$ & $99.6 \pm 3.5$ \\
Stickiness between grains & $76.6 \pm 16.6$ & $55.4 \pm 12.2$ & $82.5 \pm 4.4$ \\
Springiness & $59.0 \pm 7.7$ & $49.3 \pm 7.6$ & $55.2 \pm 4.2$ \\
Cohesiveness & $69.9 \pm 8.4$ & $49.4 \pm 10.2$ & $68.0 \pm 7.3$ \\
Hardness & $56.1 \pm 4.7$ & $51.7 \pm 6.3$ & $43.5 \pm 8.3$ \\
Uniformity of bite & $93.3 \pm 5.2$ & $65.9 \pm 10.0$ & $91.6 \pm 9.7$ \\
Cohesiveness of mass & $90.8 \pm 4.1$ & $83.1 \pm 12.8$ & $107.8 \pm 5.8$ \\
Moisture absorption & $65.5 \pm 13.1$ & $64.7 \pm 6.3$ & $70.5 \pm 7.6$ \\
Residual loose particles & $68.9 \pm 5.4$ & $75.1 \pm 8.9$ & $55.7 \pm 11.1$ \\
Toothpack & $71.5 \pm 9.4$ & $51.2 \pm 15.1$ & $66.4 \pm 7.2$ \\
\hline
\end{tabular}

increasingly reliant on product profiles. The capacity to measure these attributes in an efficient and quantitative manner can also help set standards that can be used for developing policy and trade recommendations to capture the cooking and eating quality properties of rice in varietal development programs. These rice quality recommendations will be handy as rice-growing countries continue to strive to supply domestic and export needs.

\section{Additional files}

Additional file 1: Table S4. Phenotype data of grain quality cooking and eating quality parameters, rapid viscosity analyzer, advance rheometry and texture attributes of core collection panel. (XLSX $66 \mathrm{~kb}$ )

Additional file 2: Figure S1. Storage $\left(\mathrm{G}^{\prime}\right)$ and loss moduli $\left(\mathrm{G}^{\prime \prime}\right)$ curves of GQ00043-PLT1298 (1:2 W/vflour: water ratio) obtained during heating and cooling steps in a rheometer. The parameters defined in therheometry profiles are described in Table 1. Figure S2. A typical two-compression TPA curve obtained from a texture analyzer. Hardness $(\mathrm{kg})$ is peak force of the first compression ( $\mathrm{H} 1$ ). Adhesiveness is the negative force area of the first bite.Cohesiveness is the ratio of the positive force area during the second compression portion to that during thefirst compression (A2/A1). Springiness is defined as the ratio of $\mathrm{T} 2$ to $\mathrm{T} 1$, where $\mathrm{T} 1$ is total distance travelledby the probe on downstroke and $\mathrm{T} 2$ is distance traveled on downstroke by the probe from point of samplecontact to end of downstroke (T2/T1). (ZIP $214 \mathrm{~kb}$ )

Additional file 3: Table S1. Designations of samples used for sensory evaluation, selected from the three clusters. Table S2. Data used for multivariate analyses for the samples selected for sensory evaluation. 
Table S3. Sensory evaluation scores ${ }^{1}$ for the fifteen rice accessions from the three clusters. (DOCX $30 \mathrm{~kb})$

\section{Abbreviations \\ AC: Amylose content; ADH: Adhesiveness; $\mathrm{COH}$ : Cohesiveness; DSC: Differential scanning calorimetry; FV: Final viscosity; GT: Gelatinisation temperature; HRD: Hardness; LO: Lift-off; MLR: Multinomial Logistic Regression; PC: Protein content; PV: Peak viscosity; RVA: Rapid Visco-Analysis; SB: Setback; SPR: Springiness; TPA: Texture profile analysis; TV: Trough viscosity}

\section{Acknowledgments}

The authors thank Valerien Pede, IRRI Agri-Food Policy Platform, for assistance in conducting MLR and in interpreting the results. The authors also acknowledge support of other IRRI staff, Lucena Samadio for conducting texture profile analyses; Lilia Molina and the staff of the Grain Quality and Nutrition Service Laboratory (GQNSL) for performing amylose content and RVA measurements; and Roslen Anacleto, Roldan Ilagan, Artemio Madrid, Jr., and Fernando Salisi for growing the core collection.

\section{Funding}

The cost of data collection and grain quality analyses were covered through the funds available from the Global Rice Science Partnership (GRISP), the CGIAR Research Program on Rice Agri-Food Systems (RICE), Stress-Tolerant Rice for Africa and South Asia (STRASA) Phase III for BMGF funding, and the Philippine Department of Science and Technology's Accelerated Science and Technology Human Resource Development Program National Science Consortium (ASTHRDP-NSC).

\section{Availability of data and materials}

All data supporting the conclusions of this article are provided as figures, tables and supplementary figures.

\section{Authors' contributions}

NS and RPC conceived and designed the experiments. CJD performed experiments and analysed the data together with RPC. All authors wrote the paper. All authors read and approved the final manuscript

\section{Authors information}

RPC holds a PhD and work as a research scientist in the area of food science at International Rice Research Institute (IRRI). CJD completed MSc and worked in the area of texture and advance rheometry. NS holds a PhD and is employed as Head of Grain Quality and Nutrition Center at IRRI.

\section{Ethics approval and consent to participate}

The International Rice Research Institute currently does not have an Institutional Review Board. All participants in the sensory evaluation part of the study gave written consent prior to the sensory evaluation and had the option to terminate their participation at any point of the study. No minors participated in the sensory evaluation sessions.

\section{Consent for publication}

All subjects participated in sensory evaluation gave consent to publish the work.

\section{Competing interests}

All Authors declare that they have no competing interests.

\section{Publisher's Note}

Springer Nature remains neutral with regard to jurisdictional claims in published maps and institutional affiliations.

\section{Author details}

'International Rice Research Institute (IRRI), College, Los Baños, Laguna, Philippines. ${ }^{2}$ Present address: Pangasinan State University, Bayambang, Pangasinan, Philippines.
Received: 26 April 2018 Accepted: 10 September 2018

Published online: 10 October 2018

\section{References}

Ahmed J, Ramaswamy HS, Ayad A, Alli I (2008) Thermal and dynamic rheology of insoluble starch from basmati rice. Food Hydrocoll 22(2):278-287

Allahgholipour M, Ali AJ, Alinia F, Nagamine T, Kojiima Y (2006) Relationship between rice grain amylose and pasting properties for breeding better quality rice varieties. Plant Breed 125:357-362

American Association of Cereal Chemists Inc (2000) Approved methods of the American Association of Cereal Chemists, 10th edn. American Association of Cereal Chemists, St. Paul

Bao IS (2008) Accurate measurement of pasting temperature by the rapid ViscoAnalyser: a case study using rice flour. Rice Sci 15(1):69-72

Bao JS, Shen S, Sun M, Corke H (2006) Analysis of genotypic diversity in the starch physicochemical properties of nonwaxy rice: apparent amylose content, pasting viscosity and gel texture. Starch - Stärke 58:259-267

Bett-Garber KL, Champagne ET, McClung AM, Moldenhauer KA, Linscombe SD, McKenzie KS (2001) Categorizing rice cultivars based on cluster analysis of amylose content, protein content, and sensory attributes. Cereal Chem 78(5): $551-558$

Boualaphanh C, Calingacion MN, Cuevas RP, Jothityangkoon D, Sanitchon J, Fitzgerald MA (2011) Yield and quality of traditional and improved Lao varieties of rice. SciAsia 37(2):89-97

Brandt MA, Skinner EZ, Coleman JA (1963) Texture profile method. J Food Sci 28(4):404-409

Breiman L (2001) Random forests. Mach Learn 45(1):5-32

Cagampang GB, Perez CM, Juliano BO (1973) A gel consistency test for eating quality of rice. J Sci Food Agri 24:1589-1594

Calingacion MN, Laborte AG, Nelson A, Resurreccion AP, Concepcion JC, Daygon VD, Mumm R, Reinke R, Dipti S, Bassinello PZ, Manful J, Sophany S, Lara KC, Bao J, Xie L, Loaiza K, El-hissewy A, Gayin J, Sharma N, Rajeswari S, Manonmani S, Rani NS, Kota S, Indrasari SD, Habibi F, Hosseini M, Tavasoli F, Suzuki K, Umemoto T, Boualaphanh C, Lee HH, Hung YP, Ramli A, Aung PP, Ahmad R, Wattoo Jl, Bandonill E, Romero M, Brites CM, Hafeel R, Lur H-S, Cheaupun K, Jongdee S, Blanco P, Bryant R, Thi Lang N, Hall RD, Fitzgerald MA (2014) Diversity of global rice markets and the science required for consumer-targeted rice breeding. PLoS One 9(1):e85106

Calpe C (2004) International trade in rice: recent developments and prospects. World Rice Research Conference, Tsukuba, Japan, In

Champagne ET, Bett KL, Vinyard BT, McClung AM, Barton FE, Moldenhauer KA, Linscombe SD, McKenzie KS (1999) Correlation between cooked rice texture and rapid Visco Analyser measurements. Cereal Chem 76(5):764-771

Champagne ET, Bett-Garber KL, Fitzgerald MA, Grimm CC, Lea J, Ki O, Jongdee S, Xie L, Bassinello P, Resurreccion AP, Ahmad R, Habibi F, Reinke RF (2010) Important sensory properties differentiating premium rice varieties. Rice 3(4): 270-281

Champagne ET, Bett-Garber KL, Thomson JL, Fitzgerald MA (2009) Unraveling the impact of nitrogen nutrition on cooked rice flavor and texture. Cereal Chem 86(3):274-280

Champagne ET, Lyon BG, Min BK, Vinyard BT, Bett KL, Barton FE, Webb BD, McClung AM, Moldenhauer KA, Linscombe S, McKenzie KS, Kohlwey DE (1998) Effects of postharvest processing on texture profile analysis of cooked rice. Cereal Chem 75(2):181-186

Chen M-H, Bergman CJ, Pinson SRM, Fjellstrom RG (2008) Waxy gene haplotypes: associations with pasting properties in an international rice germplasm collection. J Cereal Sci 48(3):781-788

Chung H-J, Liu Q, Lee L, Wei D (2011) Relationship between the structure, physicochemical properties and in vitro digestibility of rice starches with different amylose contents. Food Hydrocoll 25(5):968-975

Cuevas RP, Daygon VD, Corpuz HM, Reinke RF, Waters DLE, Fitzgerald MA (2010) Melting the secrets of gelatinisation temperature in rice. Func Plant Bio 37: 439-447

Cuevas RP, Pede VO, McKinley J, Velarde O, Demont M (2016) Rice grain quality and consumer preferences: a case study of two rural towns in the Philippines. PLoS One 11(3):e0150345

Dixit S, Kumar B, Singh A, Ashoka R (2015) An application of multinomial logistic regression to assess the factors affecting the women to be underweight and overweight: a practical approach. Intl J Health Sci Res 5(10):11-17 
Doutch J, Bason M, Franceschini F, James K, Clowes D, Gilbert EP (2012) Structural changes during starch pasting using simultaneous rapid Visco analysis and small-angle neutron scattering. Carb Poly 88(3):1061-1071

Fitzgerald MA, Martin M, Ward RM, Park WD, Shead HJ (2003) Viscosity of rice flour: a rheological and biological study. J Agri Food Chem 51(8):2295-2299

Garcia DM, Bassinello PZ, Ascheri DRP, Ascheri JLR, Trovo JB, Cobucci RMAC (2011) Cooking quality of upland and lowland rice characterized by different methods. Food Sci Tech 31(2):341-348

Goodwin HL Jr, Koop LA, Rister ME, Miller RK, Maca JV, Chambers E, Hollingsworth M, Bett KL, Webb BD, McClung AM (1996) Developing a common language for the U.S. rice industry: Linkages among breeders, producers, processors, and consumers. In: TAMRC Consumer Product Market Research Report. Agri Market Res Center 43, Texas

Graham R (2002) A proposal for IRRI to establish a Grain Quality and Nutrition Research Center. In: IRRI Discussion Paper Series No. 44. International Rice Research Institute, Los Banos, p 15

Hori K, Suzuki K, lijima K, Ebana K (2016) Variation in cooking and eating quality traits in Japanese rice germplasm accessions. Breed Sci 66:309-318

Hsu S, Lu S, Huang C (2000) Viscoelastic changes of rice starch suspensions during gelatinization. J Food Sci 65(2):215-220

International Organization for Standardization (2007a) ISO 6647-2: 2007Rice-Determination of amylose content—Part 2: Routine methods, p 10 International Organization for Standardization (2007b) ISO 6647-1: 2007Rice_-Determination of amylose content_Part 1: Reference method, p 11

Iturriaga LB, de Mishima BL, Añon MC (2006) Effect of amylose on starch pastes viscoelasticity and cooked grains stickiness in rice from seven argentine genotypes. Food Res Int 39(6):660-666

Juliano BO (2006) Trends in rice quality demand in Asia. In: Sumarno, Suparyono, Fagi, AM, Adnyana, MO (eds) Rice industry. Cuture and Environment. Indonesian Center for Rice Research, Subang, West Java, pp 43-53

Juliano BO, Perez CM, Resurreccion AP (2009) Apparent amylose content and gelatinization temperature types of Philippine rice accessions in the IRRI Gene Bank. Phil Agri Sci 92(1):106-109

Kumar I, Khush GS (1986a) Gene dosage effect of amylose content in rice endosperm. Jap J Genet 61:559-568

Kumar I, Khush GS (1986b) Genetics of amylose content in rice (Oryza sativa L.). J Genet 65(1-2):1-11

Li H, Prakash S, Nicholson TM, Fitzgerald MA, Gilbert RG (2016) The importance of amylose and amylopectin fine structure for textural properties of cooked rice grains. Food Chem 196:702-711

Li K, Bao JS, Corke H, Sun M (2017) Association analysis of markers derived from starch biosynthesis related genes with starch physicochemical properties in the USDA rice mini-core collection. Front Plant Sci 8:424

Liaw A, Wiener M (2002) Classification and regression by random Forest. R News 2(3):18-22

Louppe G, Wehenkel L, Sutera A, Geurts P (2013) Understanding variable importances in forests of randomized trees. In: Burges CJC, Bottou L, Welling M, Ghahramani Z, Weinberger KQ (eds) Adv Neural Info Processing Systems, pp 431-439

Lyon BG, Champagne ET, Vinyard BT, Windham WR (2000) Sensory and instrumental relationships of texture of cooked rice from selected cultivars and postharvest handling practices. Cereal Chem 77(1):64-69

Madhu B, Ashok NC, Balasubramanian S (2014) A multinomial logistic regression analysis to study the influence of residence and socio-economic status on breast cancer incidences in southern Karnataka. Intl J Math Stat Inv 2(5):1-8

Mandala IG (2012) Viscoelastic properties of starch and non-starch thickeners in simple mixtures or model food. In: de Vicente J (ed) Viscoelasticity: from theory to biological applications. IntechOpen. Rijeka, Croatia, pp 217-236

Martin M, Fitzgerald MA (2002) Proteins in rice grains influence cooking properties. J Cereal Sci 36(3):285-294

Miura S, Crofts N, Saito Y, Hosaka Y, Oitome NF, Watanabe T, Kumamaru T, Fujita N (2018) Starch synthase lla-deficient mutant Rice line produces endosperm starch with lower gelatinization temperature than japonica Rice cultivars. Front Plant Sci 9:645. https://doi.org/10.3389/fpls.2018. 00645 eCollection 2018

Musyoki MA, Kioko WF, Mathew NP, Daniel A, Muriira KG, WN D, Felix M, Chemutai LR, Mwenda NS, Kiambi MJ, Ngithi NL (2015) Genetic diversity studies on selected rice (Oryza sativa) genotypes based on amylose content and gelatinization temperature. Adv Crop Sci Tech 3:5
Okadome H (2005) Application of instrument-based multiple texture measurement of cooked milled-rice grains to rice quality evaluation. Jap Agri Res Quart 39(4):261-268

Okadome H, Toyoshima H, Shimizu N, Suzuki K, Ohtsubo K (2005) Quality prediction of rice flour by multiple regression model with instrumental texture parameters of single cooked milled rice grains. Cereal Chem 82(4): 414-419

Pang Y, Ali J, Wang X, Franje NJ, Revilleza JE, Xu J, Li Z (2016) Relationship of rice grain amylose, gelatinization temperature, and pasting properties for breeding better eating and cooking quality of rice varieties. PLOS One 11(12):e0168483

Singh N, Kaur L, Sandhu KS, Kaur J, Nishinari K (2006) Relationships between physicochemical, morphological, thermal, rheological properties of rice starches. Food Hydrocoll 20(4):532-542

Tan Y, Corke H (2002) Factor analysis of physicochemical properties of 63 rice varieties. J Sci Food Agri 82:745-752

Tran N, Daygon VD, Resurreccion AP, Cuevas RP, Corpuz HM, Fitzgerald MA (2011) A single nucleotide polymorphism on the Waxy gene explains a significant component of gel consistency. Theor Appl Genet 123(4):519-525

Tsai ML, Lii CY (2000) Effect of hot-water-soluble components on the rheological properties of rice starch. Starch - Stärke 52(2-3):44-53

Tuaño APP, Aoki N, Fujita N, Oitome NF, Merca FE, Juliano BO (2014) Grain and starch properties of waxy and low-apparent amylose Philippine Rices and of NSIC Rc222. Phil Agri Sci 97(4):329-339

Tuaño APP, Regalado MJC, Juliano BO (2016) Grain quality of rice in selected retail stores and supermarkets in the Philippines. Intl J Phil Sci Tech 9(1):15-22

Unnevehr L, Juliano BO, Perez CM (1985) Consumer demand for rice grain quality in Southeast Asia. In: International Rice research conference. International Rice Research Institute, Los Baños, Philippines, pp 15-23

Vandeputte GE, Derycke V, Geeroms J, Delcour JA (2003) Rice starches. II. Structural aspects provide insight into swelling and pasting properties. J Cereal Sci 38(1):53-59

Villareal CP, Maranville JW, Juliano BO (1991) Nutrient content and retention during milling of brown Rices from the international Rice research institute. Cereal Chem 68(4):437-439

Xie L, Chen N, Tang S, Luo J, Jiao G, Hu P (2011) Use of Mixolab in predicting rice quality. Cereal Chem 88(4):333-337

Yang F, Chen Y, Tong C, Huang Y, Xu F, Li K, Corke H, Sun M, Bao JS (2014) Association mapping of starch physicochemical properties with starch synthesis-related gene markers in nonwaxy rice (Oryza sativa L.). Mol Breeding 34(4):1747-1763

Yoenyongbuddhagal N, Noomhorm A (2002) Effect of physicochemical properties of high-amylose Thai rice flours on vermicelli quality. Cereal Chem 79(4):481-485

Zaidul ISM, Norulaini NAN, Omar AKM, Yamauchi H, Noda T (2007) RVA analysis of mixtures of wheat flour and potato, sweet potato, yam, and cassava starches. Carb Poly 69(4):784-791

Ziegler A, König IR (2014) Mining data with random forests: current options for realworld applications. WIREs Data Mining and Knowledge Discovery 4(1):55-63

\section{Submit your manuscript to a SpringerOpen ${ }^{\circ}$ journal and benefit from:}

- Convenient online submission

- Rigorous peer review

- Open access: articles freely available online

- High visibility within the field

- Retaining the copyright to your article

Submit your next manuscript at $\boldsymbol{\nabla}$ springeropen.com 